\title{
ASSESSING FUTURE TEACHERS' KNOWLEDGE ON FRACTIONS: WRITTEN TESTS VS CONCEPT CARTOONS
}

Libuše Samková

Faculty of Education, University of South Bohemia, Jeronýmova 10, České Budějovice, Czech Republic, lsamkova@pf.jcu.cz

\author{
Highlights \\ - $\quad$ Concept Cartoons - a tool for observing future primary school teachers' knowledge \\ - They can provide us with information that might not be obtained through standard written tests
}

\begin{abstract}
The contribution investigates opportunities that an educational tool called Concept Cartoons can offer in future teachers' education, namely in comparison with word problems in standard written tests. The referred empirical study was conducted in two separated consecutive stages, with two groups of future primary school teachers (the first one from the Czech Republic, and the second one from Slovakia). The participants of the first stage solved four word problems (T1, T2, T3, T4) with increasing difficulty within the written test, and a problem with a similar structure and difficulty as T3 but in the Concept Cartoon form. The second stage of the study served as a complementary stage, its participants solved only the word problem T3 and the Concept Cartoon. In both stages, the comparison of results and solution procedures revealed many participants who mastered the word problem(s) but displayed a fundamental misconception when working with the Concept Cartoon. Two thirds of the participants presented noncorresponding responses to these two corresponding tasks: they solved one of them correctly and the other one incorrectly. All of the problems in the study were based on the part-whole interpretation of fractions, the revealed misconception consisted of incorrect determination of the whole.
\end{abstract}

\section{Keywords}

Concept Cartoons, fractions, future primary school teachers, problem solving, word problems
Samková L. (2018) “Assessing Future Teachers’ Knowledge on Fractions: Written Tests vs Concept Cartoons”, Journal on Efficiency and Responsibility in Education and Science, Vol. 11, No. 3, pp. 45-52, online ISSN 1803-1617, printed ISSN 23362375, doi: 10.7160/eriesj.2018.110301.

\section{Introduction}

During university preparation, mathematics content knowledge of future teachers is often assessed through standard written tests where future teachers solve various calculation tasks and word problems. In my recent work, I have studied an educational tool called Concept Cartoons and its opportunities in assessing various aspects of future teachers' knowledge, e.g. their way of grasping situations related to word problems (Samková and Tichá, 2015), the openness of their approach to mathematics (Samková and Tichá, 2016b), their reasoning (Samková and Tichá, 2017b), problem posing skills (Samková and Tichá, 2016b, 2017b), informal foundations of pedagogical content knowledge (Samková, 2018a). One of the first studies (Samková and Tichá, 2015) showed how problems assigned in the Concept Cartoon form might become a valuable alternative to standardly assigned word problems. It also revealed one future teacher who incorrectly solved an unequal partition problem assigned in the Concept Cartoon form but correctly solved its alternative version assigned as a word problem. A subsequent interview of this future teacher showed that she had just learned the method needed for solving unequal partition word problems by rote, without understanding. And so, naturally, a question arose whether this happened as an exceptional case or whether Concept Cartoons could generally provide us with information on mathematics content knowledge that might not be obtained by word problems in standard written tests. This question led to a qualitative empirical study that will be reported here.

As in previous studies, the here reported study will focus on future primary school teachers, i.e. future teachers for pupils from 6 to 11 years of age. The mathematical topic in the centre of the study will be the topic of fractions, namely the partwhole interpretation of fractions. The topic of fractions is very important for future primary school teachers, there are many empirical studies reporting that the topic belongs to the most difficult ones for pupils (Lamon, 1999; Ryan and Williams, 2011; Steffe and Olive, 2010) as well as for future teachers and teachers (Cramer and Lesh, 1988; Ma, 1999; Depaepe et al., 2015; Singer, Ellerton and Cai, 2015). Drawing on this fact, the topic of fractions often plays a significant role in studies investigating questions related to partial understandings, sources of learner misconceptions and error-handling practices of teachers. For instance, Kazemi and Stipek (2001) employ the topic of fractions to illustrate their results on how to use errors to reconceptualise problems, explore contradictions and pursue alternative strategies of teaching, Schleppenbach et al. (2007) employ it to discuss the opportunities to create an error-friendly environment in the classroom. This brings us to the possibility to enable errors as opportunities for learning (Ingram, Pitt and Baldry, 2015), to the question of what is the role of misconceptions in the classroom (Nesher, 1987) and back to the idea of Concept Cartoons as one of the ways how partially represent the classroom environment to future teachers and teachers by presenting them possible pupils conceptions and misconceptions. Such an arrangement links this contribution also with the topic of teachers' ability to notice (van Es and Sherin, 2002; Star and Strickland, 2008), especially with the issue of noticing mathematics specific phenomena (Vondrová and Žalská, 2015).

From the perspective of ERIE conferences and ERIES Journal, the topic of the contribution is related to educational issues like students' solving strategies (Novotná and Vondrová, 2017) and knowledge-based reasoning (Uličná, 2017). It directly follows the issues presented by me and my colleague at the two previous 
ERIE conferences (Samková and Tichá, 2016a, 2017a), and in the last two volumes of the ERIES Journal (Samková and Tichá, 2016b, 2017b).

This paper has been developed as an extension of the contribution (Samková, 2018b). I took advantage of my recent internship in a neighbouring country and enriched the research published in (Samková, 2018b) with further data.

The text is organized as follows: at the beginning, it presents word problems on fractions in the framework of the primary school curriculum and introduces participants of the study and the employed tools (written tests, Concept Cartoons). Then it describes the course of data collection and data analysis, presents findings, and discusses them.

\section{Fractions at the primary school level}

The study reported here concerns two neighbouring countries with a partly shared history of education: the Czech Republic and Slovakia. At the primary school level in the Czech Republic, the topic of fractions consists of the concept of a fraction per se, which is fundamentally interpreted through part-whole or part-part interpretations. The part-whole interpretation is based on partitioning either a continuous quantity or a set of discrete objects into equal-sized subparts or subsets (NÚV, 2015; Behr et al., 1983; Lamon, 1999). In word problems, pupils usually deal with requirements to ascertain a fractional part for a given whole, a whole for a given fractional part, or a complement of a given fractional part to a whole. In more difficult tasks they also deal with requirements to ascertain a fractional part when another fractional part with the same whole is given. As the time goes, the pupils meet more complex tasks combining several different fractional parts (either with the same whole, or with different wholes), and also tasks that are based on one or more fractional changes (each of them is applied either on a whole or on a part). To solve such tasks successfully, the pupils as well as the teacher have to be well oriented in the situation described in the word problem and have to decide properly about the parts and the whole in the situation. For task samples and their attributes see Table 1.

The tasks in Table 1 are sorted by difficulty, having T3 identified as more difficult than $\mathrm{T} 2$ since tasks with fractional changes generally appear to trigger much more errors and misconceptions than tasks without them. The reasons probably come from two sources. First, the errors and misconceptions might relate to linguistics: the tasks without a fractional change often use the preposition "of" in the text to refer to the whole in the described situation (4/7 of all pupils, $3 / 8$ of his potatoes, $4 / 5$ of the rest), but the tasks with the fractional change do not use this preposition, and so the decision about the whole is much more complicated there. In Czech and Slovak languages (which are the languages of the study participants), the syntax of these matters differs only a little from the English syntax, and the core of the problem stays the same. The second source of errors and misconceptions might consist in the fact that the concept of a fractional change combines additive and multiplicative structures together, and this combination results in the absence of symmetry that would be present if the structures were treated separately: the statement "A is 4 more than B" that expresses an additive structure describes the same situation as the statement " $\mathrm{B}$ is 4 less than $\mathrm{A}$ ", the statement " $\mathrm{A}$ is 4-times more than $\mathrm{B}$ " that expresses a multiplicative structure describes the same situation as the statement " $\mathrm{B}$ is 4-times less than A", but the statements " $\mathrm{A}$ is $1 / 4$ more than $\mathrm{B}$ " and " $\mathrm{B}$ is $1 / 4$ less than $\mathrm{A}$ " that express a structure related to a fractional change describe two diverse situations - the first situation having $\mathrm{B}$ as the whole and the latter one having $\mathrm{A}$ as the whole, so that the quarters are not equal. Such asymmetry is also reported by Lamon (1999) in so called shrinking and enlarging within the topic of percentages: here the statement " $\mathrm{A}$ is $25 \%$ more than $\mathrm{B}$ " does not correspond to the statement " $\mathrm{B}$ is $25 \%$ less than $\mathrm{A}$ ". For more about linguistic issues related to fractional changes and different structure and difficulty levels of tasks on fractions at primary school level in the Czech Republic see (Samková and Tichá, 2017b).

\begin{tabular}{|c|c|c|}
\hline T1 & $\begin{array}{l}\text { There are } 16 \text { girls in our class, } \\
\text { which is } 4 / 7 \text { of all pupils. How } \\
\text { many boys are there? }\end{array}$ & $\begin{array}{l}\text { one whole, two different } \\
\text { fractional parts, one fractional } \\
\text { part being a complement of the } \\
\text { other, requirement to ascertain } \\
\text { a fractional part when another } \\
\text { fractional part with the same } \\
\text { whole is given, the number in the } \\
\text { assignment is not the whole, the } \\
\text { text uses the preposition "of" to } \\
\text { refer to the whole }\end{array}$ \\
\hline T2 & $\begin{array}{l}\text { A greengrocer came to a market } \\
\text { for two days. On Monday he sold } \\
3 / 8 \text { of his potatoes, on Tuesday } \\
4 / 5 \text { of the rest. How much of the } \\
\text { potatoes was not sold? How many } \\
\text { kilograms of potatoes did the } \\
\text { greengrocer bring to the market } \\
\text { provided he sold } 200 \text { kilograms } \\
\text { on Tuesday? }\end{array}$ & $\begin{array}{l}\text { two different wholes, one of } \\
\text { the wholes is a complement of } \\
\text { a fractional part to the other } \\
\text { whole, requirement to ascertain } \\
\text { a fractional part for a given whole, } \\
\text { requirement to ascertain a whole } \\
\text { for a given fractional part, the } \\
\text { number in the assignment is none } \\
\text { of the wholes, the text uses the } \\
\text { prepositions "of" to refer to the } \\
\text { wholes }\end{array}$ \\
\hline T3 & $\begin{array}{l}\text { A bookseller discounted the } \\
\text { price of a book by a quarter to } 60 \\
\text { crowns. How many crowns did the } \\
\text { book cost before the discount? }\end{array}$ & $\begin{array}{l}\text { one whole, one fractional } \\
\text { change (decrease) of the whole, } \\
\text { requirement to ascertain the state } \\
\text { before the change for a given } \\
\text { state after the change and a given } \\
\text { fractional change, the number in } \\
\text { the assignment is not the whole, the } \\
\text { text does not use the preposition } \\
\text { "of" to refer to the whole }\end{array}$ \\
\hline $\mathrm{T} 3 *$ & $\begin{array}{l}\text { Today's audience at the athletic } \\
\text { stadium equals } 8000 \text {. It's a quarter } \\
\text { more than yesterday. What was } \\
\text { yesterday's audience? }\end{array}$ & $\begin{array}{l}\text { one whole, one fractional } \\
\text { change (increase) of the whole, } \\
\text { requirement to ascertain the state } \\
\text { before the change for a given } \\
\text { state after the change and a given } \\
\text { fractional change, the number in } \\
\text { the assignment is not the whole, the } \\
\text { text does not use the preposition } \\
\text { "of" to refer to the whole }\end{array}$ \\
\hline T4 & $\begin{array}{l}\text { A breeder keeps rabbits. Currently, } \\
1 / 3 \text { of his rabbits are white, and } \\
\text { the others are grey. The breeder } \\
\text { plans to give } 3 \text { grey rabbits to his } \\
\text { neighbour today, and get } 3 \text { white } \\
\text { ones for exchange. After this } \\
\text { exchange, the proportion of white } \\
\text { rabbits will rise to } 4 / 9 \text {. How many } \\
\text { rabbits does the breeder have? }\end{array}$ & $\begin{array}{l}\text { one whole, two changes (decrease, } \\
\text { increase) of two fractional parts } \\
\text { that complement each other, } \\
\text { requirement to ascertain the } \\
\text { whole from a given state of one } \\
\text { of the fractional parts before } \\
\text { the change, a given state of this } \\
\text { fractional part after the change and } \\
\text { a given change, the number in the } \\
\text { assignment is not the whole, the } \\
\text { text uses the preposition "of" to } \\
\text { refer to the whole }\end{array}$ \\
\hline
\end{tabular}

Table 1: Samples of various word problems on fractions, increasing code numbers in the first column refer to increasing difficulty of the problems; attributes of the problems are listed in the last column

In Slovakia, the topic of fractions is present in the primary school curriculum only at the propaedeutic level, mainly in the part-whole interpretation: in the sense of halving, thirding or quartering a given whole, and of ascertaining a whole for a given half, third or quarter (Švecová et al., 2017).

Nevertheless, in both countries future primary school teachers meet the topic of fractions in its entirety (i.e. all interpretations of fractions including ratios and percentages, and operations on 
fractions) during their teacher preparation content courses. And, like elsewhere in the world, they tend to provide misconceptions on the topics, especially on issues related to the part-whole interpretation (Hošpesová and Tichá, 2015; Samková and Tichá, 2017b; Pavlovičová and Švecová, 2017).

\section{Materials and Methods}

This study addresses the research question "Can Concept Cartoons provide us with information on mathematics content knowledge that might not be obtained through word problems in standard written tests?"

\section{Participants}

The research was conducted with two groups of participants, university students of the master degree program for future primary school teachers. The first group consisted of 23 future primary school teachers from the University of South Bohemia in České Budějovice, Czech Republic, and the second group consisted of 44 future primary school teachers from the Constantine the Philosopher University in Nitra, Slovakia. In both cases, I worked with completely all students that came to the compulsory lesson where data were collected.

\section{Diagnostic instruments}

As diagnostic instruments in my study, I used a standard written test and a Concept Cartoon. The written test included four word problems with increasing difficulty: T1, T2, T3 and T4 from Table 1. The participants from the first group had to solve all four tasks, with a requirement to solve them within the framework of primary school mathematics ${ }^{1}$ (i.e. they were not allowed to use unknowns and equations in their solution procedures, nor topics outside primary school mathematics such as percentages). The participants from the second group had to solve only the task T3, no restrictions nor recommendations on the solution procedure were communicated to them.

With the Concept Cartoon, all the participants obtained a bubbledialogue picture related to the task $\mathrm{T} 3 *$ from Table 1; the picture is presented in Figure 1.

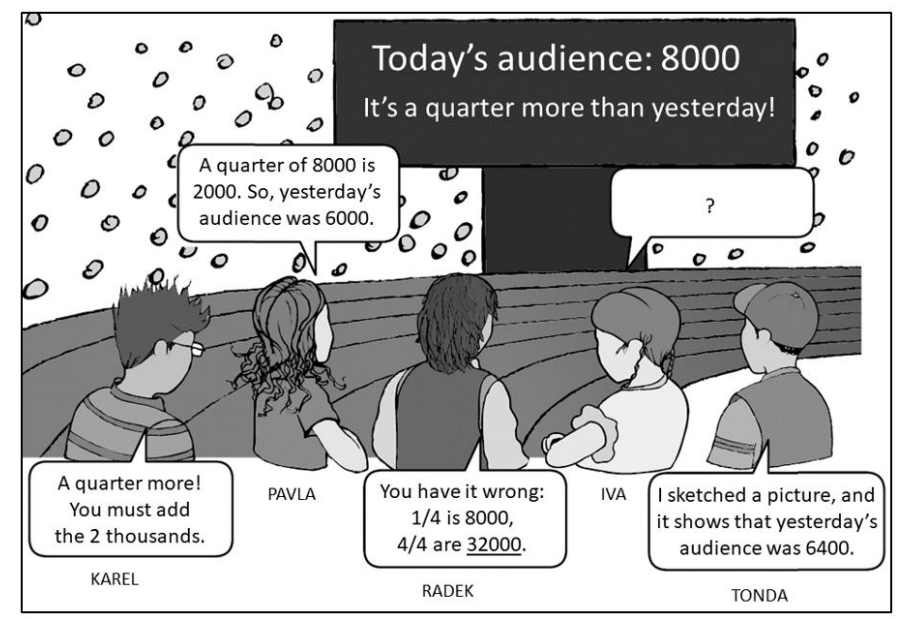

Figure 1: A Concept Cartoon related to the task T3*; (source of the template of children with empty bubbles: Dabell, Keogh and Naylor, 2008: 2.16)

The participants were asked to decide which children in the picture were right and which were wrong and to justify their decision. The form of the work with the Concept Cartoon was the same as with the test: individual and written. The task T3*

1 In the sense of the primary school curriculum in the Czech Republic, which is the country of the first group of participants. The framework of primary school mathematics will be employed in this sense for the rest of the text. has a similar structure and a similar difficulty as the task T3, see the attributes of the two tasks given in Table 1.

The method of how to use Concept Cartoons for diagnosing knowledge of future teachers and the particular Concept Cartoon from Figure 1 had been already tested previously (Samková and Tichá, 2017b; Samková, 2018a). This particular Concept Cartoon combines three bubbles containing procedures and results (Pavla, Karel, Radek), and a bubble introducing a result with a reference to a missing drawing that leads to the result (Tonda). The three bubbles with procedures and results are based on three most frequent incorrect solutions of the task T3*, and the fourth bubble without a procedure refers to a correct solution.

\section{Data collection and data analysis}

The study was performed in two separated consecutive stages: the first stage with the first group of participants, and the second stage with the second group of participants. From each of the participants, the data were collected at one time: first, the participant solved the written test with the word problem(s), and submitted it, and immediately after he/she worked on the Concept Cartoon.

For the first group of participants, the test served as a part of the course assessment, i.e. it took place after the topic of fractions was discussed at lectures and properly practised at course seminars. For the second group of participants, the test was an optional activity; the course with the topic of fractions and its assessment preceded my survey.

At the beginning of data analysis, I processed data from individual stages separately. When analysing data from the written test, I initially registered combinations of word problems that were successfully solved by individual participants (applies only to data from the first stage) and then monitored strategies that the participants used during the solution process. When analysing data from the Concept Cartoon, I initially registered combinations of bubbles that were chosen by individual participants as right, combinations of bubbles that were chosen as wrong, and strategies that the participants used in their justifications. Afterwards, I analysed mutual relations between data obtained via the word problem(s) and data obtained via the Concept Cartoon, and mutual relations between data obtained during the first and second stages.

\section{Results}

\section{Written test - the first stage}

Initial analysis of data related to written tests handled by the first group of participants showed that for all of the participants the success directly depended on the difficulty of the tasks:

- T4 was successfully solved only by participants who succeeded in T1, T2 and T3;

- T3 was successfully solved only by participants who succeeded in $\mathrm{T} 1$ and $\mathrm{T} 2$;

- T2 was successfully solved only by participants who succeeded in $\mathrm{T} 1$.

Such an arrangement allowed me to divide participants into five categories according to their success, and I labelled the categories by numbers corresponding to the most difficult tasks that the participants successfully solved: WT0 (no task solved), WT1 (only T1 solved), WT2 (only T1 and T2 solved), WT3 (only T1, T2 and T3 solved), WT4 (all tasks solved). There were 2 participants in WT0, 6 in WT1, 2 in WT2, 7 in WT3, and 6 in WT4. 
In further analysis, I focused in detail on the task T3. The first stage participants in their solutions to T3 offered four different numbers as results and achieved these results by six different procedures. The results and samples of corresponding procedures are presented in Table 2.

\begin{tabular}{|l|l|l|l|}
\hline \multicolumn{1}{|c|}{$80[13]$} & \multicolumn{1}{|c|}{$75[6]$} & \multicolumn{1}{c|}{$240[3]$} & \multicolumn{1}{c|}{$300[1]$} \\
\hline $\begin{array}{l}60 \ldots 3 / 4 \\
60: 3=20 \ldots 1 / 4 \\
20 \cdot 4=\mathbf{8 0} \ldots 4 / 4\end{array}$ & $\begin{array}{l}60: 4=15 \ldots 1 / 4 \\
60+15=\mathbf{7 5}\end{array}$ & $\begin{array}{l}1 / 4=60 \\
4 / 4=60 \cdot 4=\mathbf{2 4 0}\end{array}$ & $\begin{array}{l}60 \cdot 4=240 \\
240+60=\mathbf{3 0 0}\end{array}$ \\
\hline & $\begin{array}{l}\text { now } \ldots 4 / 4 \ldots 60 \\
\text { before } \ldots 5 / 4 \\
\\
\end{array}$ & $\begin{array}{l}1 / 4 \text { from } 60= \\
=60 \cdot 4: 1=\mathbf{2 4 0}\end{array}$ & \\
& $15 \cdot 5=\mathbf{7 5}$ & $=60$ & \\
\hline
\end{tabular}

Table 2: Various results and various solution procedures to the task $\mathrm{T} 3$ given by the first stage participants, the column with the correct result is shaded; numbers of participants with a given result are indicated in square brackets

We can see that both the procedures leading to the result 75 proceeded from the incorrect identification of the whole; they were based on a similar misconception as in the Pavla's bubble. The first procedure leading to the result 240 might proceed from careless reading and understanding the text as "to a quarter" instead of "by a quarter"; a similar misconception as in the Radek's bubble. The second procedure leading to the result 240 combined two diverse misconceptions: an incorrect decision to calculate a quarter of 60 to get the result, and a calculation error consisting of reversing the order of division and multiplication when calculating the quarter of 60 . The source of the decision to calculate a quarter of 60 is not clear, it might be a consequence of a strategy "take all numbers from the assignment, and do something with them" which sometimes appears among students (Samková and Tichá, 2015). The source of the calculation error probably lies in an unsuccessful effort to learn the calculation procedure by rote. The procedure leading to the result $300 \mathrm{might}$ have a similar source as the first procedure of 240 - a response to a signal "before discount" causing the need for addition as the next step in the procedure. But the participant with the 300 result did not specify any fractions in the solution procedure, so that the source might also come from the "take all numbers" strategy mentioned above.

\section{Concept Cartoon - the first stage}

Since the Concept Cartoon was not compulsory and had no influence on the assessment of the course, seven of the first stage participants decided not to take part in this activity. There was no relation between their success in the written test and the decision not to take part in the Concept Cartoon part: each of the WT categories was represented among those who refused, by one or two participants. Due to the lack of data from these participants, I had to remove them from the study. So that only 16 participants remained for the first stage analysis involving the Concept Cartoon.

According to responses to the Concept Cartoon, the first stage participants might be divided into two categories: those who expressed the opinion that Tonda was right and the others wrong, and those who expressed the opinion that Pavla was right and the others wrong. All the opinions were justified by presenting a solution procedure that the participants considered as correct. Three of the solution procedures were also accompanied by illustrative pictures: one picture as a support for Pavla, and two pictures as a support for Tonda. Samples of solution procedures and illustrative pictures are shown in Table 3.

\begin{tabular}{|c|c|}
\hline Tonda [9] & Pavla [7] \\
\hline $\begin{array}{l}\text { Only Tonda recognized that } 8000 \text { is } \\
\text { a quarter more than the whole. The } \\
\text { whole is } 4 / 4 \text {, a quarter more is } 5 / 4 \text {. } \\
8000 \ldots 5 / 4 \\
8000: 5=1600 \ldots 1 / 4 \\
8000-1600=6400\end{array}$ & $\begin{array}{l}\text { Pavla is true. } \\
\text { altogether... } 8000 \\
\text { yesterday... a quarter less than } \\
8000: 4=2000 \\
8000-2000=\mathbf{6 0 0 0}\end{array}$ \\
\hline $\begin{array}{l}8000: 5=1600 \\
1600 \cdot 4=6400\end{array}$ & $\begin{array}{l}\text { Tonda: Where is the picture? } \\
\text { Incorrect answer! } \\
\text { The picture should be this way: } \\
8000: 4=2000 \text { came extra } \\
2000 \cdot 3=\mathbf{6 0 0 0} \text { yesterday }\end{array}$ \\
\hline
\end{tabular}

Table 3: Various responses to the Concept Cartoon given by the first stage participants, the column with correct responses is shaded; numbers of participants who agreed with a given child are indicated in square brackets; translation of texts in embedded pictures: včera $=$ yesterday, základ $=$ the whole, navíc $=$ extra

\section{Mutual relations - the first stage}

According to combinations of results to the task T3 and opinions to the Concept Cartoon, the first stage participants might be divided into 7 categories, as shown in the diagram in Figure 2. Due to the similarities between the task T3 and the task behind the Concept Cartoon, some of the combinations might be labelled as corresponding, the others as non-corresponding. The corresponding combinations consisted either of both responses correct ( $80 \&$ Tonda) or of both responses incorrect and based on a similar misconception (75 \& Pavla). Such combinations accounted for half of the participants. The other half of the participants displayed non-corresponding combinations of responses: either both incorrect but based on different misconceptions (240 \& Pavla, $300 \&$ Pavla), or one correct and one incorrect ( $80 \&$ Pavla, $75 \&$ Tonda, $240 \&$ Tonda). The most frequent non-corresponding combination was $80 \&$ Pavla.

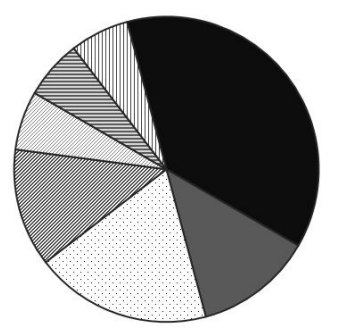

$$
\begin{aligned}
& \text { - } 80 \text { \& Tonda } \\
& \square 75 \text { \& Pavla } \\
& \square 80 \text { \& Pavla } \\
& \text { 圆75\& Tonda } \\
& \text { ๑240 \& Tonda } \\
& \text { 目 } 240 \& \text { Pavla } \\
& \text { ๑300 \& Pavla }
\end{aligned}
$$

Figure 2: Combinations of responses to the word problem T3 and to the Concept Cartoon given by the first stage participants, corresponding combinations are colored, non-corresponding combinations are dotted or hatched, $n=16,2017$ (source: own calculation)

Three of the non-corresponding combinations are noteworthy: 80 \& Pavla, 75 \& Tonda, and 240 \& Tonda. Participants with a combination $80 \&$ Pavla presented themselves successfully in the written test: they managed to solve the tasks T1, T2 and T3 (i.e. they belonged to the category WT3), some of them even solved the task T4 (category WT4). But responses to the Concept Cartoon showed a misconception about fractions: all of them incorrectly identified the whole in a task, presented incorrect solution procedures, and offered justifications for these incorrect procedures. Even the justifications did not warn them that something might not be right in their procedures.

Participants with combinations 75 \& Tonda and $240 \&$ Tonda were all weak in the written test: one of them did not succeed 
in any of the test tasks (category WT0), the others successfully solved only the task T1 (category WT1). But with the Concept Cartoon, they all offered a correct solution procedure justifying the Tonda's bubble. Such an arrangement is surprising; the reason for the discrepancy might lie in the different format of the Concept Cartoon (e.g. in the fact that the numerical result of the correct solution appears inside one of the bubbles) or in the non-compulsory nature of the work with the Concept Cartoon or somewhere else; an exact determination would require more data.

The other combinations were more or less expected: good test solvers that responded correctly to the Concept Cartoon ( $80 \&$ Tonda), and weak test solvers that responded incorrectly to the Concept Cartoon (75 \& Pavla, 240 \& Pavla, 300 \& Pavla).

\section{Written test - the second stage}

The second stage participants in their solutions to T3 offered four different numbers as results. They achieved these results by seven different procedures within the framework of primary school mathematics, and by six different procedures outside the framework of primary school mathematics. Two participants failed to complete the task, two participants offered the correct result but without a procedure, and two participants offered just an incorrect result 75 without a procedure. The results with samples of solution procedures are presented in Tables 4 and 5.

\begin{tabular}{|l|l|l|l|}
\hline \multicolumn{1}{|c|}{$80[12]$} & \multicolumn{1}{c|}{$75[1]$} & \multicolumn{1}{c|}{$240[4]$} & \multicolumn{1}{c|}{$180[1]$} \\
\hline $3 / 4=60$ & $60: 4=15$ & $1 / 4=60$ & $1 / 4 \ldots 60$ \\
$60: 3=20$ & $60+15=\mathbf{7 5}$ & $4 / 4=\mathbf{2 4 0}$ & $3 \cdot 60=\mathbf{1 8 0}$ \\
$60+20=\mathbf{8 0}$ & & & \\
\hline $3 / 4 \ldots 60$ crowns & & & \\
$1 / 4 \ldots 20$ crowns & & & \\
$4 / 4 \ldots \mathbf{8 0}$ crowns & & & \\
\hline $3 / 4 \ldots 60$ & & & \\
$3 / 4+1 / 4=\mathbf{8 0}$ & & & \\
\hline $1 / 4$ of $80=20$ & & & \\
$80-20=60$ & & & \\
$\mathbf{8 0}$ & & & \\
\hline
\end{tabular}

Table 4: Various results and various solution procedures to the task $\mathrm{T} 3$ given by the second stage participants within the framework of primary school mathematics, the column with the correct result is shaded; numbers of participants with a given result are indicated in square brackets

\begin{tabular}{|c|c|c|}
\hline $80[4]$ & $80[14]$ & $240[2]$ \\
\hline$x-1 / 4 x=60$ & $100 \%-25 \%=75 \%$ & \\
$4 x-x=240$ & $75 \%=60$ & $x \cdot 1 / 4=60$ \\
$3 x=240$ & $75: 60=100: x$ & $x=\mathbf{2 4 0}$ \\
$x=\mathbf{8 0}$ & $6000: 75=x$ & \\
& $x=\mathbf{8 0}$ & \\
$3 / 4$ of the price $\ldots 60$ crowns & $75 \% \ldots 6$ crowns & $1 / 4 x=60$ \\
$4 / 4=$ whole price $\ldots x$ & $100 \% \ldots x$ crowns & $x=\mathbf{2 4 0}$ \\
$x: 60=4 / 4: 3 / 4$ & $x: 60=100: 75$ & \\
$3 / 4 x=60 \cdot 4 / 4$ & $75 x=6000$ & \\
$3 / 4 x=60$ & $x=\mathbf{8 0}$ & \\
$3 x=240$ & & \\
$x=\mathbf{8 0}$ & & \\
\hline
\end{tabular}

Table 5: Various results and various solution procedures to the task T3 given by the second stage participants outside the framework of primary school mathematics, the columns with the correct result are shaded; numbers of participants with a given result and similar solution procedures are indicated in square brackets

Table 4 contains procedures within the framework of primary school mathematics, and Table 5 contains procedures outside the framework of primary school mathematics (i.e. procedures using equations with one unknown, ratios, percentages). The first shaded column in Table 5 contains correct procedures that do not employ percentages, and the second shaded column contains correct procedures that employ percentages. In Table 4, the last procedure in the first column is interesting: here the participant did not solve the task but guessed or estimated its result, and then verified it.

\section{Concept Cartoon - the second stage}

According to responses to the Concept Cartoon, the second stage participants might be divided into the same two categories as in the first stage: those who agreed only with Tonda, and those who agreed only with Pavla. There were five participants who did not offer any justification for their decisions: one of them agreed with Tonda, and four agreed with Pavla. Three of the participants offered justifications via illustrative pictures, all of them as support for Pavla. The other decisions were justified by presenting a solution procedure that the participants considered as correct. Samples of solution procedures and samples of illustrative pictures are shown in Tables 6 and 7: Table 6 contains procedures within the framework of primary school mathematics, and Table 7 contains procedures outside the framework of primary school mathematics. The fourth solution procedure in the second column of Table 6 is unique: it combines a mistake in a fractional representation and a calculation mistake, and its fractional representation does not relate to any other in collected data.

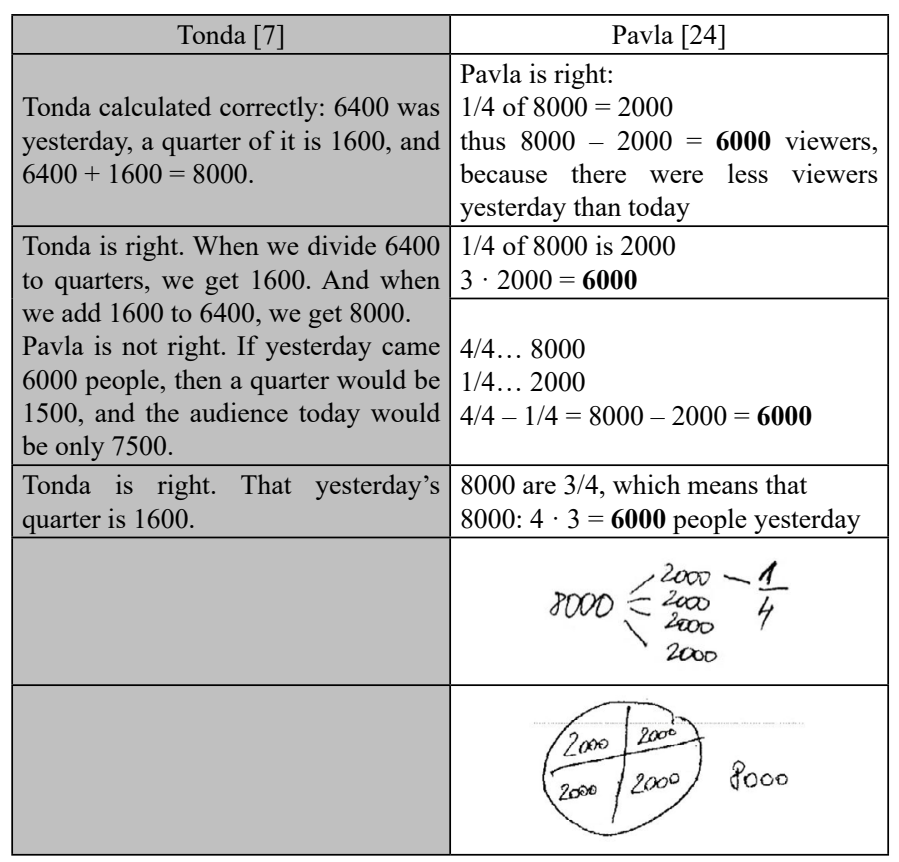

Table 6: Various responses to the Concept Cartoon given by the second stage participants within the framework of primary school mathematics, the column with correct responses is shaded; numbers of participants who agreed with a given child and offered similar solution procedures or illustrative pictures are indicated in square brackets

\begin{tabular}{|c|c|}
\hline Tonda [5] & Pavla [3] \\
\hline $125 \% \ldots 8000$ & $8000 \ldots 100 \%$ \\
$100 \% \ldots x$ & $x \ldots 75 \%$ \\
$8000 \cdot 100=125 x$ & $x: 8000=75: 100$ \\
$\mathbf{6 4 0 0}=x$ & $100 x=8000 \cdot 75$ \\
$x \cdot 5 / 4=8000$ & $100 x=600000$ \\
$x=32000: 5$ & $x=6000$ \\
$x=\mathbf{6 4 0 0}$ & \\
\hline
\end{tabular}

Table 7: Various responses to the Concept Cartoon given by the second stage participants outside the framework of primary school mathematics, the column with correct responses is shaded; numbers of participants who agreed with a given child and offered similar solution procedures are indicated in square brackets 


\section{Mutual relations - the second stage}

According to combinations of results to the task $\mathrm{T} 3$ and opinions to the Concept Cartoon, the second stage participants might be divided into 8 categories, as is shown in the diagram in Figure 3. As in the first stage, two of the combinations might be labelled as corresponding, and the others as non-corresponding. This time, the corresponding combinations accounted only for less than a third of the second stage participants, and almost half of the second stage participants accounted for the most frequent non-corresponding combination $80 \&$ Pavla (these participants solved the word problem correctly but the Concept Cartoon incorrectly).

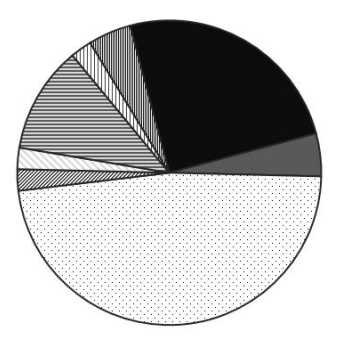

$$
\begin{aligned}
& \text { - } 80 \text { \& Tonda } \\
& \square 75 \text { \& Pavla } \\
& \square 80 \text { \& Pavla } \\
& \text { 国 } 75 \text { \& Tonda } \\
& \square 240 \text { \& Tonda } \\
& \text { 目 } 240 \& \text { Pavla } \\
& \text { m } 180 \text { \& Pavla } \\
& \text { 血 no answer \& Pavla }
\end{aligned}
$$

Figure 3: Combinations of responses to the word problem T3 and to the Concept Cartoon given by the second stage participants; corresponding combinations are colored, non-corresponding combinations are dotted or hatched, $n=44,2018$ (source: own calculation)

\section{The first stage vs the second stage}

Results from the first and second stages differ in two noticeable ways. Firstly, in solution procedures that the stage participants as a whole used to solve the task $\mathrm{T} 3$, and secondly, in correspondence between solution procedures that individual stage participants used to solve the word problem T3 and the corresponding Concept Cartoon problem. The first stage participants were less successful than the second stage participants in solving the task $\mathrm{T} 3$, and most of the second stage correct solution procedures belonged outside the primary school mathematics. In the first stage, the most frequent correct solution procedure was the only correct one that appeared in data, but in the second stage, there were four different correct procedures.

In the first stage, the corresponding combinations of procedures to the word problem and the Concept Cartoon appeared in half of the cases, in the second stage only in less than a third. The prevailing combination in the first stage was the corresponding combination 80 \& Tonda, while the prevailing combination in the second stage was the non-corresponding combination $80 \&$ Pavla.

All the above differences are probably consequences of different contexts (educational as well as organizational) in which the first and second stages of the survey took place: the curricula are not the same in the two countries, nor the course of the university training for future primary school teachers, also the organization of data collection varied in range of tasks assigned to the participants and (non)existence of additional requirements on solution methods.

Regardless of the context differences, the key finding is the same for both stages: there appeared a substantial group of successful solvers of the word problem T3 that solved the corresponding problem in the Concept Cartoon form incorrectly. In the first stage, this group accounts for one third of all the successful solvers of T3, and in the second stage for almost two thirds.

\section{Discussion}

The results of this study enriched the puzzle on "How can we meaningfully employ Concept Cartoons in future teacher education" by another piece of knowledge. They give a positive answer to the research question "Can Concept Cartoons provide us with information on mathematics content knowledge that might not be obtained through word problems in standard written tests?"

In contrast with standard written tests, Concept Cartoons may reveal participants who look like good test solvers capable to solve word problems of any difficulty, but their capability is just an illusion. For instance, the participants of the first stage of my study who belonged to the WT4 \& 80 \& Pavla combination of categories: they might be considered as excellently mastering the topic of fractions on the basis of the written test, but with the Concept Cartoon they displayed a fundamental misconception incorrect determination of the whole.

There are two different mechanisms that allow Concept Cartoons to uncover the written test illusion: (i) Concept Cartoons offer several alternative viewpoints on the pictured situation, so that they may break the stereotype of "favourite" or "comfortable" solution procedures that the solvers learned for the purpose of the written test, and may tempt the solvers to incline to some of the other procedures; (ii) when working with Concept Cartoons, the solvers are asked to provide justifications of their agree/disagree decisions, and so they expose their reasoning on the explored topic outside the common framework of problem solving.

These findings are important in light of the fact that the participants of the referred study were future teachers. Considering the way how Concept Cartoons make the respondents to reason not only in the framework of their "favourite" or "comfortable" interpretation of the topic but also in the framework of other interpretations, we may understand this tool as an artificially designed representation of school practice (Samková, 2018a), as a result of the process that Grossman et al. (2009) call a decomposition of practice into constituent parts. With such representations, we can engage future teachers in discussions about various aspects of teaching (mathematics content, classroom communication, etc.), and the representations may serve as mediating tools between teaching practice and future teacher education (Herbst and Chazan, 2011). In that sense, the representations may also indirectly promote the development of noticing mathematics specific phenomena and knowledge-based reasoning (van Es and Sherin, 2002; Vondrová and Žalská, 2015). As Star and Strickland (2008: 123) point out appositely, "preservice teachers have previously observed countless hours of mathematics instruction" but "their observations have been as learners of mathematics, not as teachers of mathematics". Findings of this study give a clear illustration of the quote.

From the perspective of the topic of fractions, the findings confirmed the difficulty of the topic for future primary school teachers that was reported e.g. by Cramer and Lesh (1988), Ma (1999), Depaepe et al. (2015): almost a third of the participants of the referred study did not solve correctly a word problem based on a fractional change of the whole (T3), as they did not grasp the task properly and/or did not identified properly the whole in the task. This happened also with a similar word problem (T3*) which was assigned in the Concept Cartoon form - in that case, more than two thirds of participants agreed with a bubble that identified incorrectly the whole in the task. Even the correct result that numerically appeared inside one of the other bubbles did not help. Unfortunately, the large number of unsuccessful solvers of word problems with a fractional change is not exceptional, a task similar to T3* appeared in 2015 in the Czech 
Republic as a word problem in the state matriculation exam, with only $33 \%$ of the students that solved the task correctly (Samková, 2018a). Some factors that cause the difficulty of the tasks with fractional changes have been already mentioned in the Introduction section, the others might relate to the fact that this kind of word problems rarely appears in explanatory parts of textbooks and learning materials on fractions, it is not even included in summarizing books on fractions or misconceptions (Lamon, 1999; Ryan and Williams, 2011).

From the perspective of solution strategies that the participants used when they solved the tasks, the findings meet the results of previous research where similar tasks were used (Lamon, 1999; Tichá and Macháčková, 2006; Samková, 2018a): typical correct solution procedures as well as common misconceptions appeared in solutions, some of them accompanied by visualizations.

A comparison of solution strategies and results related to the two similar tasks (T3, T3*) that were assigned in two different forms (word problem, Concept Cartoon) illustrates how diverse information can be provided by word problems and Concept Cartoons: only a third of the participants displayed corresponding responses to the two forms of problems: either both responses correct and based on a similar strategy ( $80 \&$ Tonda), or both responses incorrect and based on a similar misconception (75 \& Pavla). The remaining two thirds of participants responded correctly to one of the forms and incorrectly to the other (e.g. $75 \&$ Tonda), or responded incorrectly in both cases but the responses were based on different misconceptions (e.g. 240 \& Pavla). This finding is in line with conclusions of Novotná and Vondrová (2017) about the impact that the context of a task might have on solving strategies.

The weak point of the referred study consists in the impossibility to generalize the results. On the other side, I included as participants all future primary school teachers who came to the two compulsory lessons where data were collected - in that sense the study is representative.

\section{Conclusion}

This contribution investigated opportunities that an educational tool called Concept Cartoons could offer in future teachers' education, namely in comparison with word problems in standard written tests. From the perspective of mathematics content, it focused on the topic of fractions which again proved its difficulty for future primary school teachers.

The study confirmed the efficiency of using Concept Cartoons in future primary school teachers' education, since they may provide us with information on misconceptions that might not be obtained through standard written tests. I conducted the study with two groups of future primary school teachers from two neighbouring countries, in two diverse educational and organizational contexts. Regardless of the context differences, the key finding on the efficiency of Concept Cartoons in future primary school teachers education is the same for both stages.

\section{References}

Behr, M., Lesh, R., Post, T. and Silver, E. (1983) 'Rational number concepts', in Acquisition of mathematics concepts and processes, New York: Academic Press, pp. 91-125.

Cramer, K. and Lesh, R. (1988) 'Rational number knowledge of preservice elementary education teachers', in Proceedings of PME 88, DeKalb, Il: PME, pp. 425-431.

Dabell, J., Keogh, B. and Naylor, S. (2008) Concept Cartoons in Mathematics Education, Sandbach: Millgate House Education. Depaepe, F., Torbeyns, J., Vermeersch, N., Janssens, D., Janssen, R., Kelchtermans, G., Verschaffel, L. and Van Dooren, W.
(2015) 'Teachers' content and pedagogical content knowledge on rational numbers: a comparison of prospective elementary and lower secondary school teachers', Teaching and Teacher Education, vol. 47, pp. 82-92. http://dx.doi.org/10.1016/j. tate.2014.12.009

Grossman, P., Compton, C., Igra, D., Ronfeldt, M., Shanan, E. and Williamson, P. (2009) 'Teaching practice: A crossprofessional perspective', Teachers College Record, vol. 111, no. 9 , pp. 2055-2100.

Herbst, P. and Chazan, D. (2011) 'On creating and using representation of mathematics teaching in research and teacher development', ZDM Mathematics Education, vol. 43, pp. 1-5. http://doi.org/10.1007/s11858-011-0306-9

Hošpesová, A., Tichá, M. (2015) 'Problem posing in primary school teacher training', in Singer, F.M., Ellerton, N.F. and Cai, J. (ed.) Mathematical problem posing, New York: Springer, pp. 433-447. http://doi.org/10.1007/978-1-4614-6258-3_21

Ingram, J., Pitt, A. and Baldry, F. (2015) 'Handling errors as they arise in whole-class interactions', Research in Mathematics Education, vol. 17, pp. 183-197. http://doi.org/10.1080/147948 02.2015 .1098562

Kazemi, E. and Stipek, D. (2001) 'Promoting conceptual thinking in four upper-elementary mathematics classrooms', Elementary School Journal, vol. 102, pp. 59-80. http://doi. org/10.1086/499693

Lamon, S.J. (1999) Teaching fractions and ratios for understanding, Mahwah, NJ: LEA.

Ma, L. (1999) Knowing and teaching elementary mathematics, Mahwah, NJ: Erlbaum.

Národní ústav pro vzdělávání (NÚV), (2015) Rámcový vzdělávaci program pro základni vzdělávání, Praha: MŠMT, [Online], Available: http://www.msmt.cz/file/37052/ [5 Sep 2018].

Nesher, P. (1987) 'Towards an instructional theory: the role of student's misconceptions', For the Learning of Mathematics, vol. 7, no. 3, pp. 33-40.

Novotná, J. and Vondrová, N. (2017) 'Pupils' strategies for missing value proportional problems', in Proceedings of ERIE 2017, Prague, pp. 279-286, [Online], Available: http://erie. v2.czu.cz/en/r-13628-proceedings-2017 [5 Sep 2018].

Pavlovičová, G. and Švecová, V. (2017) 'Some misconceptions in understanding of fractions', in Proceedings of EDULEARN17 Conference, Barcelona, pp. 5463-5470. http://doi.org/10.21125/ edulearn.2017.2246

Ryan, J. and Williams, J. (2011) Children's mathematics 4-15. Learning from errors and misconceptions, Berkshire: Open University Press.

Samková, L. (2018a) 'Concept Cartoons as a representation of practice', in Mathematics Teachers Engaging with Representations of Practice. ICME-13 Monograph, New York: Springer. http://doi.org/10.1007/978-3-319-70594-1_5

Samková, L. (2018b) 'Written tests vs Concept Cartoons: the case of future teachers and fractions', in Proceedings of ERIE 2018, Prague, pp. 314-321, [Online], Available: http://erie. v2.czu.cz/en/r-13780-proceedings-2018 [5 Sep 2018].

Samková, L. and Tichá, M. (2015) 'Investigating future primary teachers' grasping of situations related to unequal partition word problems', Quaderni di Ricerca in Didattica (Mathematics), vol. 25, no. 2, pp. 295-303.

Samková, L. and Tichá, M. (2016a) 'Developing open approach to mathematics in future primary school teachers', in Proceedings of ERIE 2016, Prague, pp. 494-501, [Online], Available: http://erie.v2.czu.cz/en/r-13629-proceedings-2016 [5 Sep 2018]. 
Samková, L. and Tichá, M. (2016b) 'On the way to develop open approach to mathematics in future primary school teachers', ERIES Journal, vol. 9, no. 2, pp. 37-44. http://doi.org/10.7160/ eriesj.2016.090202

Samková, L. and Tichá, M. (2017a) 'Observing how future primary school teachers reason about fractions', in Proceedings of ERIE 2017, Prague, pp. 363-371, [Online], Available: http:// erie.v2.czu.cz/en/r-13628-proceedings-2017 [5 Sep 2018].

Samková, L. and Tichá, M. (2017b) 'On the way to observe how future primary school teachers reason about fractions', ERIES Journal, vol. 10, no. 4, pp. 93-100. http://doi.org/10.7160/ eriesj.2017.100401

Schleppenbach, M., Flevares, L.M., Sims, L.M. and Perry, M. (2007) 'Teachers' responses to student mistakes in Chinese and U.S. mathematics classrooms', Elementary School Journal, vol. 108, pp. 131-147. http://doi.org/10.1086/525551

Singer, F.M., Ellerton, N.F. and Cai, J. (2015) Mathematical problem posing, New York: Springer. http://doi.org/10.1007/9781-4614-6258-3

Star, J.R. and Strickland, S.K. (2008) 'Learning to observe: using video to improve preservice mathematics teachers' ability to notice', Journal of Mathematics Teacher Education, vol. 11, pp. 107-125. http://doi.org/10.1007/s10857-007-9063-7

Steffe, L. and Olive, J. (2010) Children's fractional knowledge, New York: Springer. http://doi.org/10.1007/978-1-4614-6258-3 Švecová, V., Pavlovičová, G., Rybanský, L'. and Klimentová, L. (2017) Reifikácia zlomkov vo vzt’ahu k osobnej potrebe štruktúry, Praha: Wolters Kluwer.

Tichá, M. and Macháčková, J. (2006) Rozvoj pojmu zlomek ve vyučování matematice, Praha: JČMF.

Uličná, K. (2017) 'Professional vision: focus on knowledgebased reasoning', in Proceedings of ERIE 2017, Prague, pp. 482-489, [Online], Available: http://erie.v2.czu.cz/en/r-13628proceedings-2017 [5 Sep 2018].

van Es, E.A. and Sherin, M.G. (2002) 'Learning to notice: scaffolding new teachers" interpretations of classroom interactions', Journal of Technology and Teacher Education, vol. 10, pp. 571-596.

Vondrová, N. and Žalská, J. (2015) 'Ability to notice mathematics specific phenomena: what exactly do student teachers attend to?', Orbis Scholae, vol. 9, no. 2, pp. 77-101. http://doi.org/10.14712/23363177.2015.81 